\title{
Observations on colour agnosia
}

\author{
M. KINSBOURNE AND ELIZABETH K. WARRINGTON
}

From the National Hospital, Queen Square, London

Wilbrand (1887) reported a patient who, though apparently able to perceive colours in the normal way, persistently misnamed them. Similarly he would misname colours characteristically associated with familiar objects. He named this defect 'amnestic colour blindness' and regarded it as 'related to aphasia'. Lewandowsky (1908) described another case, and explained the defect as resulting from a 'dissociation of the idea of the colour from that of the object'. Sittig (1921) presented a fuller case study of a patient who had sustained a left temporo-occipital shrapnel wound, resulting in a slight receptive but marked expressive aphasia, as well as an inability to pick out coloured wools to correspond to named objects or to name appropriate objects when shown a colour. Yet he was not colour blind and could recognize colours previously shown to him. He could detect pictures which had been deliberately wrongly coloured. A similar, though milder case appears to have been that of Heilbronner (1906), whose patient misnamed colours but would correctly allocate objects to colours, and 'usually' colours to objects. Goldstein and Gelb (1918) saw in their case of colour agnosia an 'impairment of the categorical attitude' in relation to colours. Their patient was reported only to be able to attach the exactly correct colour to an object and not one that merely fell into the right colour category. Lange (1936), reviewing the subject, was unable to decide whether colour agnosia is an aphasic manifestation or a true recognition defect. He did, however, point out that Goldstein and Gelb's explanation would seem to be applicable to no case other than their own.

Stengel (1948) reported two further cases, the first of which he studied in great detail. The further case presented below resembles Stengel's case 1 in many respects.

\section{CASE REPORT}

W.K., aged 65, a right-handed lorry driver, was admitted under the care of Dr. M. J. McArdle. Three weeks previously he experienced the sudden onset of a severe occipital headache radiating frontally. After about an hour it diminished in severity, but was sufficient to keep him off work and continued up to his admission. The

pain was aggravated by stooping and was associate $\overrightarrow{\mathrm{f}}$ with nausea. There was no history of trauma.

On admission, he was fully conscious and well orient $\bar{C}$ ated. He was normotensive, his visual acuity was $6 / \bar{c}$ bilaterally, his visual fields normal on perimetry, and no abnormalities were found on clinical examination of the nervous system. Skull radiographs revealed a shift of the pineal gland, which was calcified, several millimetres to the right of the midline, and the shift of midline structures was confirmed by ultra-sound testing. The cerebrospina $L$ fluid was xanthochromic and contained seven lymphow cytes, one polymorph, and $50 \mathrm{mg}$. of protein. per $100 \mathrm{ml}$ ? The Wassermann reaction was negative in blood and cerebrospinal fluid. The blood count was normal, as were the bleeding and clotting times, prothrombin level, $-\mathrm{V}$ and platelet count. Serum electrolyte levels were withint the normal range, and the electrocardiogram reveated no abnormality. The electroencephalogram shove्for flattening of background activity and loss of alptra rhythm over the left parietal area. Bilateral carothdangiograms indicated the presence of a subdural effuston over the left parietal area.

Bilateral posterior parietal burr holes were made, 迎 the contents of a left-sided subdural haematoma permitt $=$ ted to escape. The next day the patient appeared drowsy The left-sided burr hole was reopened but no more fluid $P$ appeared to have accumulated. $A$ burr hole was next made in the left temporal region and about $10 \mathrm{ml}$. of dark, watery haematoma aspirated. However, he remained mute and apparently confused, and there was now a. minimal right-sided weakness. A low pressure state waso suspected, and some normal saline was given intrathecally by the lumbar route. From then on he steadily improved, regained clear consciousness and full muscle 3 power. However, it was now found that he had difficulty in reading, in interpreting complex pictures, and in naming colours.

\section{TEST PROCEDURES AND RESULTS}

PSYCHOLOGICAL TESTING W.K. was tested on the W.A.I.S. and scored as follows:

Verbal I.Q........89

Arithmetic .......... 7

Similarities ...........9

Digit span..........9

Vocabulary.........8 On all the verbal tests a mild degree of word-finding 0 difficulty was apparent, and served to lower his scores onn Object assembly......5
Performance I.Q. . ...920 Picture completion...11 Block design .........10 Picture arrangement...6 
this scale. The pattern of the non-verbal test scores was characteristic of a person with a perceptual disability. These findings indicate that he was of average intelligence premorbidly, and there is little indication of any generalized intellectual deterioration.

He had difficulty in naming three out of 20 common objects (ruler-measurer, scissors-cutter, pen-knifepen), and in explaining the meanings of proverbs (he attempted abstract explanations). He was able to carry out double instructions. He passed Marie's three-paper test. His oral spelling was poor, with letter substitution errors. His spontaneous writing was good, and he was able to write a simple sentence to dictation without errors, but he did, however, make errors in copying a sentence of equivalent difficulty. Individual letters were copied incorrectly.

W.K. had little or no difficulty with spatial or constructional tasks. He completed the block design test at the average level. He was able to copy cubes and stars. He drew a recognizable map of England and put in towns appropriately. He was able to draw a bicycle and a plan of his house. With overlapping figures he was able to shade in the parts common to both. No elements of the Gerstmann syndrome were present.

He had great difficulty in identifying pictures illustrating moderately complex events (e.g., 'telegraph boy' from the Binet scale).

When first seen he was alexic. After a week he could read short words slowly, spelt out letter by letter, but not longer ones, because he forgot the first letters by the time he reached the end ones. He still made some errors in reading an individual letter within a word, particularly when he was trying to go too fast. Shown single letters in isolation he was always able to name them, but if given letters in a group he would make many more mistakes in naming them individually. The same was true of digits. He was then examined tachistoscopically, and his thresholds for seeing single and double letters were measured. This was repeated using other visual stimuli (shapes, silhouettes of objects, and digits). Threshold measurements are given in Table I (in msec. of exposure duration). In each case there was a large discrepancy between the threshold for a single visual form and for two visual forms. It was concluded that there was a limitation of simultaneous form perception.

\section{TABLE I}

TACHISTOSCOPIC THRESHOLDS ${ }^{1}$

\begin{tabular}{lcc} 
& Single & Double \\
\hline Letters & 10 & 640 \\
Shapes & 32 & 800 \\
Silhouettes & 40 & 1,000 \\
Digits & 16 & 50 \\
1Threshold (msec.) for correct single and double form perception.
\end{tabular}

PERCEPTION AND NAMING OF COLOURS Ishihara's test of colour vision was given. All digits were correctly identified.

Colour matching When colours (coloured wools) were presented in pairs, some identical, some slightly different, they were always correctly discriminated. In sorting coloured wools no confusion of similar colours or colours of similar brightness was ever observed. In particular, blue and green were always differentiated. When asked to match pieces of coloured wool with similar coloured objects in the room he also succeeded. Thus when comparing two colours he always correctly reported whether they were similar or different.

Perception of hue $\mathrm{He}$ was able to arrange a number (10 or more) of pieces of different coloured wools according to hue from dark to light.

Colour categorization Holmgren's wool test was administered. This consists of a number of skeins of wool of many different colours. He was asked to pick out all the reds, greens, and blues; this he did without error.

Weigl's sorting test was passed; he spontaneously sorted the pieces according to their colour.

These tests show that the perception of colours at the visuo-sensory levels was intact.

Colour naming Naming of variously coloured wools was grossly impaired. In 15 successive responses no more than six were correct when he was examined initially. On the most recent examination 11 of 15 were correct. The names for colours he gave bore no relation to the correct ones. The following are some examples: cream for green, red for blue, pink for yellow, yellow for blue.

He was repeatedly shown four blocks of four standard colours-red, blue, green, yellow-and asked to name them. In 30 trials he made 18 errors. These appeared to be random except that he frequently called the red block blue.

When successively shown two differently coloured blocks to which he had given the same name he would revise his opinion, often with little more success. Red, 'that's blue', blue, 'that's blue', 'no, they were different, this one's red (the blue) and the other's pink (the red)'.

Naming the colours of real objects was equally impaired. Here an exception was noted; black, grey, and white objects were always correctly identified in terms of their colours. Pointing to the colour of named objects proved equally difficult except as regards black, grey, and white.

He had great difficulty in naming the colours of familiar objects: One pound note, 'red'; traffic light for 'go', 'white, no blue'; daffodil, 'green'; sky, 'pale green'.

Only occasionally did he give the colour of an object correctly, though grass and a letter-box were consistently correctly called green and red respectively.

Recognition of colours and colour names W.K. had as great a difficulty in indicating a colour when its name was given as in actual colour naming. $\mathrm{He}$ was given four blocks, coloured red, blue, yellow, and green respectively; he was asked to point to the appropriate one when named. He made eight errors in 15 trials. No systematic errors were noted.

He was asked to name objects of a given colour. 'What is coloured red'? etc. In this he was often wrong, e.g., green-grass, leaf, and sky.

Identification of deliberately wrongly coloured objects was good. By use of colouring blocks, a number of pictures was prepared, each containing one or more 
incorrectly coloured items. W.K. differentiated correctly between the appropriately and inappropriately coloured objects in spite of being unable to name the colour that should have been used, or to give the name of the colour that had, in fact, been used, e.g., person with green hair: 'He's got red hair, wouldn't have red hair'. Q. 'Haven't you seen red hair?' A. 'Not that red, it's an unnatural colour'.

W.K. coloured drawings of objects by a process of trial and error. He was unable to choose the appropriately coloured crayon, but having coloured something he could say whether he had done it appropriately or not.

LEARNING NEW ASSOCIATIONS TO COLOUR NAMES Learning new associations to colour names was tested by using paired associate learning. First the number of paired associates not involving a colour name which W.K. could learn was established. He could learn three pairs of object-number combinations, but failed to learn four pairs. The pairs were: house-3; pen-2; watch-4, given in a different order at each trial.

Three pairs of colour-object and colour-number combinations were presented. Each set was done on two separate occasions, and each time the test was discontinued after 12 incorrect attempts.

A coloured block was then substituted for the colour name in the learning test. Thus W.K. was required to learn the associations between objects, names or numbers, and blocks of three different colours. These too were not remembered after 12 trials.

When these tests were repeated using 'white', 'black', and 'grey' as colour names, he was now able to learn the associations.

W.K. was also unable to learn the correct spatial position of three coloured blocks, e.g., red on the left, blue on the right, and green in the centre, after 12 attempts.

\section{DISCUSSION}

In the present case the syndrome of colour agnosia cannot be regarded as secondary to dysphasia, cortical blindness, or dementia. W.K. had no defect of speech reception, and only a very mild one for speech expression for verbal material other than colour names; and even these he produced freely, if inappropriately. He was not colour blind, and gave no evidence of the visual deficits found in cortical blindness. Standard tests revealed no generalized intellectual deterioration. Yet he could neither reliably name colours nor point out colours in response to their names. He had difficulty in stating the conventional associates of colours and of colour names, and in learning new ones. Thus he made mistakes when asked to associate familiar objects and concepts with those conventionally accompanying colours and colour names. He could not retain arbitrary associations between the colour names and other verbal categories (object names, Christian names, nonsense syllables) although he could easily retain associations between verba色 categories not including the colour names. He coul not retain arbitrary associations between the colours (presented as coloured blocks) and other non-verbas material (objects, geometrical shapes, sounds, an even positions in space). Associations between non-verbal material not including the colours were much more easily formed. Striking exceptions were 'white', 'grey', and 'black'. Both as words and a. colours these were exempt from disability. They. could readily be identified and used in paire associate learning.

True colour agnosia, in which, as here, the syndrome is not secondary to cortical blindness, has been regarded either as a limited dysphasia (Wil? brand, 1887) or as a recognition defect (Sittig, 1921) The postulated impairment of the "categorical attion tude' in respect of colours of Goldstein and Gelb (1918) cannot apply here, where the 'abstract' task of colour sorting into categories was successfully donew while the 'concrete' colour object association was. not.

W.K's disability was not limited to the use of the colour names. Non-verbal matching between colour and object proved difficult and new non-ver厑 associations could not be learnt. This suggests presence of a recognition defect.

But even in the absence of the colours themselves, W.K. had difficulty in relating the names of colofrs to conventionally or arbitrarily associated itergso This favours a limited verbal defect.

The present case therefore supports both hymo theses, while the sparing of white, grey, and blacos both as words and as colours, from involvement in the disability highlights the remarkable specificits of the syndrome. A previous instance of sparing of white, grey, and black in colour agnosia waso mentioned by Kleist (1934).

Stengel's (1948) thoroughly studied case 1 permits̊ comparison with W.K. The two patients are remarkably similar (except that Stengel's patien 8 was impaired also in relation to white, grey, and black). Stengel favoured the recognition defecto hypothesis, but he did not try the paired associate learning tests in relation to colour names, the results of which here can hardly be explained on this basis:-

If a limited defect in the use of the names of the colours underlies the syndrome of colour agnosia the apparent recognition defect may be explained assecondary to the naming difficulty. For even when use of the colour names is not demanded, these may? still, out of habit, be used. It may be that perceivedo colours are automatically verbally recoded. If the verbal recoding is innaccurate, and the patient is unaware of this (as was W.K.) he will tend to ben confused and to fail at the task. 
On this view the deficit that underlies colour agnosia in the present and comparable cases is the inability to associate colour names correctly with any other type of information. Conditioned linkages involving the colour names are broken and new ones fail to form. The colour names are easily but inappropriately evoked. Like a sensory aphasic, who cannot detect the errors in his own speech, the patient has no means of discovering his mistakes, and therefore continues unhesitatingly in his wrong use of the names of the colours. The existence of this deficit, which relates both to highly familiar and to novel associations, implies a high degree of functional differentiation within the cerebral areas subserving language, with a more precisely defined anatomical substrate than currently thought likely. In previously reported cases (Sittig, 1921; Pötzl, 1928; Kleist, 1934; Hécaen and Angelergues, 1963) and probably also in the present case, the causative lesion seems to have been posteriorly located in the dominant hemisphere, in the borderland between the area receiving visual input and the language or verbal recording area. This anatomical situation may reflect a corresponding functional differentiation of the relevant brain mechanism.

Throughout the months of observation the severity of the colour agnosia remained constant. The associated spelling dyslexia and impairment of picture interpretation, however, resolved completely. (The opposite occurred in Stengel's case.) This suggests the view that these symptoms, which have repeatedly but not constantly been reported as accompanying colour agnosia, are independent disorders based on lesions in adjacent cerebral territories. They were shown tachistoscopically to be due to a limitation of simultaneous form perception (Kinsbourne and Warrington, 1962). A novel finding was that of a limitation of simultaneous colour perception. This was perhaps another manifestation of the same deficit.

The evidence suggests that W.K. had two disabilities, a limitation of simultaneous visual percep- tion, which resolved, and colour agnosia, which persisted. The latter impaired the use both of colour information and of the names of the colours. This may be explained as a disorder impairing the recollection and formation of associations between colour names and other types of information, with resulting interference in any task in which colours or their names have to be placed in a specified context. The alternative view that here a verbal and a recognition deffect are simultaneously present cannot on this evidence be excluded.

\section{SUMMARY}

A 65-year-old right-handed man, following the formation of a left posterior subdural haematoma, developed 'spelling dyslexia' and impaired picture interpretation, which resolved, and colour agnosia, which persisted. The latter was analysed in detail, and shown to relate to the formation and retention of associative links between the colour names (and perhaps also the colours themselves) and other information.

We wish to thank Dr. M. J. McArdle for his kindness in permitting us to study and report this case, and Miss $\mathbf{M}$. James for assistance with some of the test procedures.

\section{REFERENCES}

Goldstein, K., and Gelb, A. (1918). Z. ges. Neurol. Psychiat., 41, 1. Hécaen, N., and Angelergues, R. (1963). La Cécité psychique. Masson, Paris.

Heilbronner, K. (1906). Dtsch. Z. Nervenheilk., 27, 414.

Kinsbourne, M., and Warrington, E. K. (1962). Brain, 85, 461

Kleist, K. (1934). Gehirnpathologie. Barth, Leipzig.

Lange, J. (1936). In Handbuch der Neurologie, vol. 6. edited by $O$. Bumke and O. Foerster, p. 807. Springer, Berlin.

Lewandowsky, M. (1908). Mschr. Psychiat. Neurol., 23, 488.

Pötzl, O. (1928). Die optisch-agnostischen Störungen. Deuticke, Leipzig, Vienna.

Sittig, O. (1921). Mschr. Psychiat. Neurol., 49, 63 and 159.

Stengel, E. (1948). J. ment. Sci. 94, 46.

Wilbrand, H. (1887). Die Seelenblindheit als Herderscheinung. Bergmann, Wiesbaden. 